\title{
Extraocular muscle cysticercosis: never skip steroids
}

\author{
Abhidnya Surve, Siddhi Goel, Mandeep S Bajaj, Amar Pujari
}

Department of Ophthalmology, Dr Rajendra Prasad Centre for Ophthalmic Sciences, AllMS, New Delhi, India

\section{Correspondence to Dr Amar Pujari, dramarpujari@gmail.com}

Accepted 27 December 2017

\section{DESCRIPTION}

\section{Case description}

A 16-year-old girl presented with a 2-month history of recurrent (three episodes) right upper eyelid drooping and oedema (figure 1A). Examination showed fullness in the right upper eyelid along with elevation deficit. Visual acuity was 20/20 in each eye, and anterior and posterior segments were essentially within normal limits in both the eyes. To explain the cause, ultrasonography of the orbit for extraocular muscles revealed a large cyst in the superior rectus muscle along with a central hyperechoic spot corresponding to the scolex (figure 1B). Non-contrast CT of the orbit and brain revealed inflammatory thickening of the superior rectus muscle with the central cystic area harbouring the scolex without any intracranial foci (figure 1C). Based on the history and imaging findings a diagnosis of myocysticercosis was confirmed and the patient was started on tablet prednisolone $1 \mathrm{mg} / \mathrm{kg}$ body weight from day 1 and tablet albendazole $15 \mathrm{mg} /$ $\mathrm{kg}$ from day 3 . The patient followed the protocol initially for 5 days and day 6 onwards she skipped the oral steroid medication and continued only
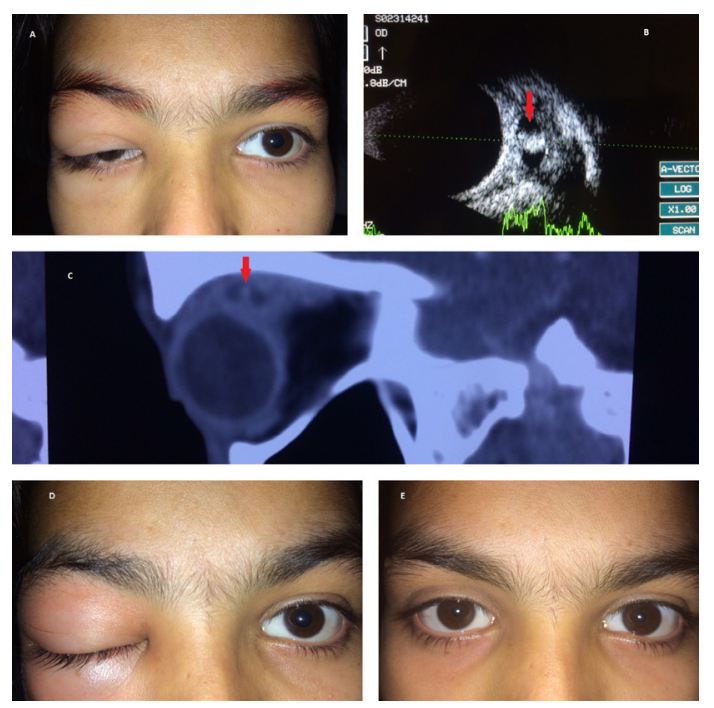

Figure 1 (A) Initial clinical presentation with recurrent swelling and drooping of upper eyelid. (B) Ultrasonography of the superior rectus muscle showing a large cyst with a central high-amplitude spike corresponding to the scolex (red arrow). (C) Sagittal view of the non-contrast CT of the orbit showing inflammatory thickening of the superior rectus muscle with the cystic cavity having the central scolex (red arrow). (D) Inflammatory swelling of the right periorbital region after the patient skipped oral steroids. (E) Complete recovery of ptosis and inflammatory signs at the end of 4 weeks. with tablet albendazole for 3 days to present later with a predominant inflammatory swelling of the eyelid, chemosis and severe elevation deficit (figure 1D). The patient was counselled again about the importance of combined medication for successful treatment and better outcome; both the medications were continued with regular weekly follow-up. At around 2 weeks the scolex had disappeared on ultrasonography. Oral albendazole was continued for 4 weeks and oral steroids were tapered over a period of 4 weeks with complete recovery of ptosis in the right eye (figure 1E).

\section{DISCUSSION}

A case of acquired ptosis with or without extraocular motility restriction having inflammatory signs should have a suspicion of extraocular myocysticercosis in endemic regions. Orbital ultrasonography and CT are able to define the muscle cyst and the scolex quite accurately in a majority of the cases. ${ }^{1}$ Successful treatment with the help of combined oral albendazole and prednisolone is proven by a number of studies. ${ }^{23}$ Albendazole mainly depletes the glycogen storage by inhibiting glucose uptake leading to death of the parasite, but subsequent to it there will be a release of toxins leading to severe inflammatory reaction; to tackle this oral steroids are given along with albendazole. In the present case, the patient was counselled about the need for combination medication before the beginning of the treatment but she defaulted and skipped oral steroids, which was indeed extremely necessary to counter the inflammation; but later with the guarded follow-up a favourable outcome was achieved. To conclude, in cases of extraocular muscle cysticercosis, a combination therapy with oral steroids and albendazole along with the appropriate dosage is necessary for a successful outcome. A close follow-up is preferred during the initial period to assess compliance to the treatment, detection of adverse events and management at the earliest.

\section{Learning points}

- Cases with extraocular myocysticercosis need thorough evaluation clinically as well as with appropriate imaging before the initiation of medical treatment.

- A close follow-up during the initial period of treatment ensures compliance, early detection of complications and management.

Contributors AS, SG, MSB and AP have evaluated the case in detail followed by appropriate medical management. AS, SG, MSB 
and $A P$ after critically evaluating the educational value of the case wrote the report together.

Competing interests None declared.

Patient consent Obtained.

Provenance and peer review Not commissioned; externally peer reviewed.

(c) BMJ Publishing Group Ltd (unless otherwise stated in the text of the article) 2018. All rights reserved. No commercial use is permitted unless otherwise expressly granted.

\section{REFERENCES}

1 Pujari A, Chawla R, Singh R, et al. Ultrasound-B scan: an indispensable tool for diagnosing ocular cysticercosis. BMJ Case Rep 2017. doi: 10.1136/bcr-2017-219346. [Epub ahead of print 21 Apr 2017].

2 Mohan K, Saroha V, Sharma A, et al. Extraocular muscle cysticercosis: clinical presentations and outcome of treatment. J Pediatr Ophthalmol Strabismus 2005:42:28-33.

3 Murthy R, Samant M. Extraocular muscle cysticercosis: clinical features and management outcome. Strabismus 2008;16:97-106.

Copyright 2017 BMJ Publishing Group. All rights reserved. For permission to reuse any of this content visit http://group.bmj.com/group/rights-licensing/permissions.

BMJ Case Report Fellows may re-use this article for personal use and teaching without any further permission.

Become a Fellow of BMJ Case Reports today and you can:

- Submit as many cases as you like

Enjoy fast sympathetic peer review and rapid publication of accepted articles

- Access all the published articles

Re-use any of the published material for personal use and teaching without further permission

For information on Institutional Fellowships contact consortiasales@bmjgroup.com

Visit casereports.bmj.com for more articles like this and to become a Fellow 